\title{
Evaluation of settlement of shallow foundations laid on unsaturated soils
}

\author{
Elis Ferreira Lopes ${ }^{1, *}$, Marcela Moreira da Rocha Moreira $^{2}$, Rosiel Ferreira Leme $^{3}$; and Francisco Chagas da Silva Filho $^{3}$ \\ ${ }^{1}$ Department of Civil Engineering, Inta-Uninta University Center, 62050-100 Sobral, Brazil \\ ${ }^{2}$ Department of Civil Engineering, Federal Institute of Education, Science and Technology of Ceara, 62940-000 Morada Nova, Brazil \\ ${ }^{3}$ Department of Hydraulic and Environmental Engineering, Federal University of Ceara, 60355-636 Fortaleza, Brazil
}

\begin{abstract}
The study presents an experimental and numerical study on an unsaturated, non-plastic and poorly graded sand, originated from Fortaleza-CE, Brazil. The numerical analyses used the Finite Element Method (FEM), were performed using the UNSTRUCT software to simulate the curve stress versus strain, considering the effect of suction on soil stiffness. Characterization and determination of the retention curve were performed through filter paper tests, which were used to determine the stress versus strain curve in a double-oedometer test. Suction was considered constant along the entire test. From the numerical analyses done with UNSTRUCT software presented satisfactory results, especially in the presence of suction profiles, that show the variation of suction along of the depth. It can be concluded that higher suction values (and soil stiffness) generate lower settlements.
\end{abstract}

\section{Introduction}

The use of Unsaturated Soil Mechanics represents a great evolution in the understanding of the mechanical behavior of soils when submitted to suction. That is: when water in the soil voids coexists with air, the water pressure must be lower than atmospheric pressure, also under traction. Thus, suction has an important influence on strength and compressibility parameters, and it is represented in numerical modelling by the effective stress equations for unsaturated soils, whose deformability modules depend, in addition to the active compression stresses, on the level of suction in the soil. The determination of these parameters, as a function of suction, occurs through laboratory and field tests, or can be estimated, when these tests are performed under unsaturated conditions (as usually don't occurs in classical Soil Mechanics).

When you want to make any prediction of soil deformation, whether caused by moisture variation, alleviation or increased stresses, it is necessary to analyse the soil's elasticity, so the use of constitutive modelling is important for engineering practice.

The use of constitutive models in earthy materials is performed with elastic and elastoplastic models, for example. In the elastoplastic models, the theory of critical state, initially proposed for saturated clayey soils, can be used and extended to unsaturated soils.

The proposal of elastic and elastoplastic models for unsaturated soils has had great growth since its implementation in programs that use the Finite Element Method (FEM), making possible to simulate the soil behavior in a more realistic way, in various practical situations and unsaturated conditions. An example is the program UNSTRUCT, which uses a non-linear elastic model for both saturated and unsaturated segments in its stress-strain analysis. The work is restricted to elasticity (reversible behaviour), that could be non-linear.

This article includes experimental and numerical studies on unsaturated soils, and regarding the experimental analyses, characterization and double-oedometer tests were performed, as well as the determination of the retention curve, through the filter paper method. The numerical analyses used was the Finite Element Method (FEM), using the UNSTRUCT software (Miranda, 1988 [1]; Silva Filho, 1998[2]). The soil assessed in this research came from the Experimental Field of Geotechnics at the Federal University of Ceará, in Northeast Brazil.

The numerical analyses were all performed after the estimation of suction and moisture profiles, for the determination of loads and settlements in predicting the behaviour of a hypothetical shallow foundation laid on a soil with different suction profiles.

\section{Literature Review}

\subsection{Elastic Model Adopted to Consider the Effect of Suction}

The UNSTRUCT program performs stress-strain analysis of saturated and unsaturated soils using the finite element method, adopting the plane-strain state. Considering that the stiffness behavior varies with the suction and the level of stresses, the calculation of the initial stresses is carried out by neglecting the displacements, because it is the initial state in situ.

The stress and strain states are generated by: (a) adding external loads; (b) moisture variation; (c) deformation of

\footnotetext{
* Corresponding author: elis f.lopes@hotmail.com
} 
collapsible and expansive unsaturated soils; and (d) percolation forces and hydrostatic thrust in the saturated zone.

The program UNSTRUCT uses the same principles already considered by Leme (2015) [3], Silva Filho (1998) [2] and Miranda (1988) [1]. The analyses of the unsaturated zone are carried out in terms of total stresses, and in the saturated zone, in terms of effective stresses. The total stresses are considered the excess over the air pore pressure $\left(u_{\mathrm{a}}\right)$, which were always considered equal to zero, by Miranda (1988) [1].

For the unsaturated soil, the equations of the plane-strain state in equilibrium are (Eqs. 1 and 2):

$$
\begin{aligned}
& \frac{\partial\left(\sigma_{x}-u_{a}\right)}{\partial \mathrm{x}}+\frac{\partial \tau_{x y}}{\partial x}+b_{x}=0 \\
& \frac{\partial\left(\sigma_{y}-u_{a}\right)}{\partial y}+\frac{\partial \tau_{x y}}{\partial y}+b_{y}=0
\end{aligned}
$$

Where: $\sigma$ is the total normal stress; $\tau_{\mathrm{xy}}-$ shear strength; $u_{\mathrm{a}}-$ air pore pressure, assumed as zero; and $\mathrm{b}_{\mathrm{x}}, \mathrm{b}_{\mathrm{y}}-$ mass forces per volume unity, due to the initial soil self weight or to variations in the specific weight, as a result of changes in the soil moisture.

For the saturated soil, the equations of the plane-strain state in equilibrium are (Eqs. 3 and 4):

$$
\begin{aligned}
& \frac{\partial\left(\sigma_{x}-u_{w}\right)}{\partial \mathrm{x}}+\frac{\partial \tau_{x y}}{\partial x}+b_{x}=0 \\
& \frac{\partial\left(\sigma_{y}-u_{w}\right)}{\partial y}+\frac{\partial \tau_{x y}}{\partial y}+b_{y}=0
\end{aligned}
$$

Where: $u_{\mathrm{w}}-$ water pore pressure; and $\mathrm{b}_{\mathrm{x}}, \mathrm{b}_{\mathrm{y}}$ - mass forces per volume unity, due to the initial soil self-weight or to water effects, including percolation forces and the hydrostatic thrust.

The constitutive relations for unsaturated soils, under conditions of plane-strain state, are (Eqs. 5, 6 and 7):

$$
\begin{aligned}
& d \varepsilon_{x}=\frac{1}{E_{u}} d\left(\sigma_{x}-u_{a}\right)-\frac{v}{E_{u}} d\left(\sigma_{y}+\sigma_{z}-2 u_{a}\right)+\frac{1}{H} d\left(u_{a}-u_{w}\right) \\
& d \varepsilon_{y}=\frac{1}{E_{u}} d\left(\sigma_{y}-u_{a}\right)-\frac{v}{E_{u}} d\left(\sigma_{x}+\sigma_{z}-2 u_{a}\right)+\frac{1}{H} d\left(u_{a}-u_{w}\right)
\end{aligned}
$$

$$
d \varepsilon_{z}=0
$$

Where: $\sigma$ is the total normal stress; $\varepsilon$ is the strain; $v$ is the Poisson's ratio; H - elastic modulus associated with variations in suction; $E_{S}$ - elastic modulus of the saturated curve of the double-oedometer test; $\mathrm{E}_{0}$ is elastic modulus for the lowest moisture condition (highest suction value); $\mathrm{E}_{\mathrm{u}}$ which is obtained by interpolating $\mathrm{E}_{0}$ and $\mathrm{E}_{\mathrm{S}} ;\left(\mathrm{u}_{\mathrm{a}}-\mathrm{u}_{\mathrm{w}}\right)-$ soil suction to which $\mathrm{E}_{\mathrm{u}}$ is calculated.

Miranda (1988) [1] proposed the model by using data from the double-oedometer test of Jennings and Knight (1957) apud Miranda (1988) [1], it is possible to carry out the analysis of the variation of the soil volume in planestrain state, as a function of the variation of the matric suction. The elastic modulus for the lowest moisture condition (highest suction value) is called $\mathrm{E}_{0}$, as shown in Eq. 8. For saturated soils, it is called $E_{S}$ (Eq. 9), and for unsaturated soils, $E_{u}$, which is obtained by interpolating $\mathrm{E}_{0}$ and $\mathrm{E}_{\mathrm{S}}$, as shown in Eq. 10:

$$
\begin{gathered}
E_{0}=\frac{(1-v)(1-2 v)\left(\sigma_{v}-u_{a}\right)_{F}}{(1-v) \Delta \varepsilon_{U F}} \\
E_{S}=\frac{(1+v)(1-2 v)\left(\sigma_{v}-u_{a}\right)_{F}}{(1-v) \Delta \varepsilon_{S 0}+\Delta \varepsilon_{S F}} \\
E_{u}=\frac{E_{0}}{\left(1-\frac{E_{0}}{E_{S}}\right)\left[\frac{\left(u_{a}-u_{w}\right)}{\left(u_{a}-u_{w}\right)_{0}}-1\right]+1}
\end{gathered}
$$

where: $\Delta \varepsilon \mathrm{UF}$ - variation of strain, corresponding to ( $\sigma_{v}$ $\left.u_{a}\right) f$, with the unsaturated sample of the double-oedometer test; $\Delta \varepsilon s 0$ - variation of strain, corresponding to $\left(\sigma_{v}-u_{a}\right)=$ 0 , with the saturated sample of the double-oedometer test; $\Delta \varepsilon S F$ - variation of strain, corresponding to $\left(\sigma_{v}-u_{a}\right) f$, with the saturated sample of the double-oedometer test; $\left(u_{a^{-}}\right.$ $\left.u_{w}\right)_{0}$ - initial suction of the soil sample, used to define $\mathrm{E}_{0}$ (assumed as constant); and $\left(u_{a}-u_{w}\right)$ - soil suction to which $\mathrm{E}_{\mathrm{u}}$ is calculated.

Fig. 1 schematically shows the calculation of the moduli $\mathrm{E}_{0}, \mathrm{E}_{\mathrm{u}}, \mathrm{E}_{\mathrm{S}}$, in the graphic of vertical strain $\varepsilon$ versus total vertical stress $\left(\sigma_{\mathrm{v}}-\mathrm{u}_{\mathrm{w}}\right)$. In this figure, only one condition of simple linear behavior is presented, although it is possible that the analysis be performed with the variation of the elasticity modulus, by considering segments of stresses defined in the double-oedometer test.

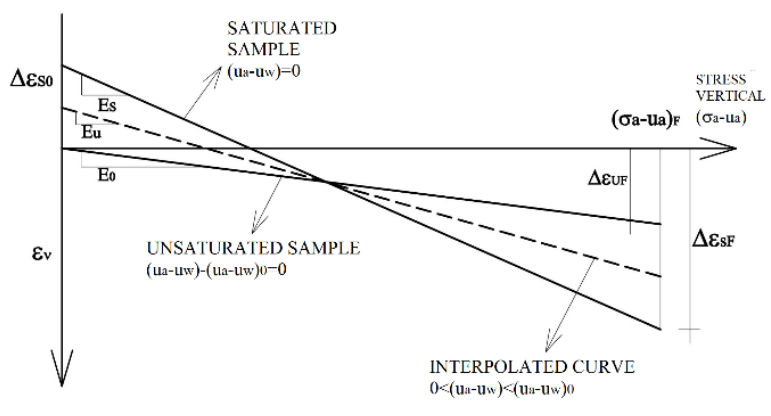

Fig. 1. Calculation of $\mathrm{E}_{0}$, Es, $\mathrm{E}_{\mathrm{u}}$.

The constitutive law for saturated soils, under conditions of plane-strain state, is composed by Equations 11, 12 and 13:

$$
\begin{gathered}
d \varepsilon_{x}=\frac{1}{E_{S}} d\left(\sigma_{x}-u_{w}\right)-\frac{v}{E_{S}} d\left(\sigma_{y}+\sigma_{z}-2 u_{w}\right) \\
d \varepsilon_{y}=\frac{1}{E_{S}} d\left(\sigma_{y}-u_{w}\right)-\frac{v}{E_{S}} d\left(\sigma_{x}+\sigma_{z}-2 u_{w}\right) \\
d \varepsilon_{z}=0
\end{gathered}
$$


Where: $E_{S}$ - elastic modulus of the saturated curve of the double-oedometer test.

The program also determines the increase in the specific weight due to the moisture variation of the unsaturated soil (Eqs. 14):

$$
\Delta \gamma=\Delta \theta \gamma_{w}
$$

Where: $\Delta \theta$ - variation of volumetric moisture; and $\gamma_{\mathrm{w}}-$ specific weight of water.

The effect of water in the saturated region is determined as a mass force:

$$
\vec{F}=-\operatorname{grad} u_{w}
$$

Such force contains the percolation forces and the hydrostatic thrust, distributed by the nodes of the finite element mesh. When considered, it is not necessary to include the weight of water as an external force (Silva Filho, 1998 [2]).

\section{Materials and Methods}

\subsection{Location of study site}

All the analyses and the tests performed for the present work were conducted using the soil collected from the Experimental Field of Geotechnics, located at the Campus do Pici of the Federal University of Ceara (UFC), Northeast Brazil.

\subsection{Laboratory Tests}

Laboratory tests were performed at the Laboratory of Soil Mechanics and Paving of the Federal University of Ceara. Both disturbed and undisturbed samples were collected from the Experimental Field, at a depth of $0.8 \mathrm{~m}$ below ground level. The undisturbed specimens were wrapped in a paraffin-coated tissue, so that there was no loss of moisture, and packed in a wooden box filled with wood chips, to ensure the integrity of the sample during transportation. Fig. 2 shows the details of this process.

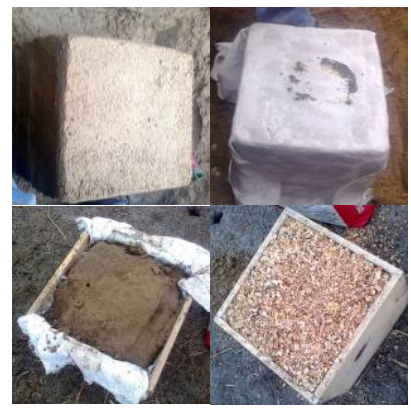

Fig. 2. Sample collecting.

After transporting the soil to the laboratory, the samples were prepared, under the regulations of ABNT NBR 6457:2016, in order to proceed with the characterization tests and the verification of the acting suction, which was determined as a function of soil moisture, i.e.: from the definition of the retention curve, obtained through the filter paper test.

\subsubsection{Filter paper test}

This test was performed with undisturbed samples, in order to preserve soil structure, due to its influence on the suction-moisture ratio. The molds used were steel rings, with diameter of $50 \mathrm{~mm}$ and height of $20 \mathrm{~mm}$. Drying procedures were also performed.

Each soil sample was carefully molded using the metal rings, and then a filter paper - whose dimensions were a little larger than the lower ring circumference - was put in contact with the soil sample, and also attached to its sides with adhesive tape, in order to avoid any loss of material. After that, the soil-containing rings were laid, for about two hours, in a flask with a thin layer of water, in order to moisten the soil and allow saturation to occur by capillarity.

After being saturated, the specimens were put in a cool and airy place for moisture loss, until they reached the desired moisture values. This process was controlled by their weight variation as time passed by, and the decrease in moisture was monitored using a $0.01 \mathrm{~g}$ precision scale for a few hours, until the process was completed.

When reaching the desired moisture, the specimens were tested according to the procedures of ASTM D 5298-16, with the implementation of some changes suggested by Marinho (2000) [4] and Rios (2006) [5], as described below.

In this study, the procedure used in the filter paper test consisted of placing two filter papers on the soil sample (see Fig. 3), which was a little different from the recommendations of the ASTM D 5298-16, that advises the use three filter papers: two papers external to one in the middle, used to prevent the adhering of soil particles to it, which was the actual paper used to measure the sample suction.

The adopted procedure in study this is consisted of using only two filter papers, as shown in Fig. 3. The paper on top was actually the one used to measure the soil suction. This configuration was adopted by Leme (2015) [3], with satisfactory results being obtained, which confirms that the test procedure remains efficient, and the moisture equilibrium between the soil and the filter paper is achieved.

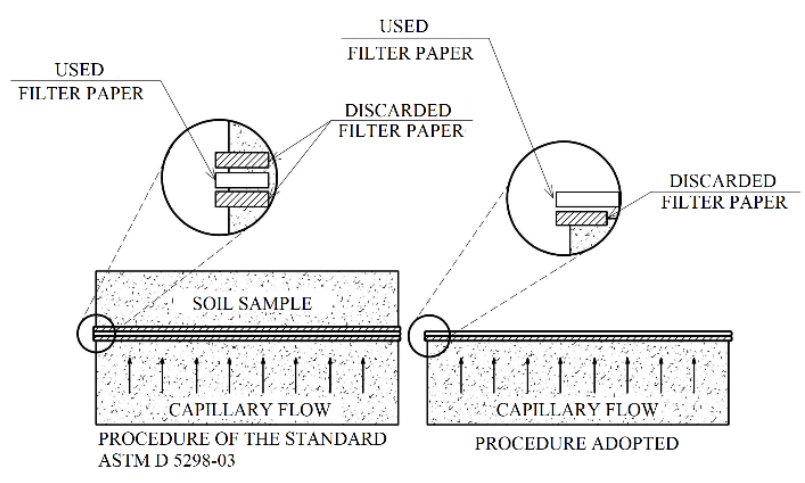

Fig. 3. Comparation between the recommended by the standard and the process actually used in the filter paper test. 
Subsequently, sample and papers were wrapped in three layers: a layer of plastic film, a layer of aluminium foil, and a closing layer of plastic film, in order to avoid any significant change in the moisture of the sample until the equilibrium. Afterwards, the samples were stored in a polystyrene box, thus ensuring the thermal insulation of the specimens. The period of equalization between paper and soil was of 7 days, as prescribed by ASTM D 529816.

After the requested time for the equalization, the test was concluded, by weighing the filter paper on a precision scale of $0.0001 \mathrm{~g}$. An important point is that the filter paper was removed from the original pack and quickly weighed, aiming to avoid any variation in its moisture. Then the papers were oven dried for 24 hours, and again weighed. Proposed by Chandler et al. (1992) [6], Equations 16 and 17 show the calibration expressions used in this test to determine suction:

$$
\begin{aligned}
& \Psi=10^{6.05-2.48 \log (w)} \text { for } \quad w>47 \% \\
& \Psi=10^{4.84-0.0622 w} \text { for } \quad w \leq 47 \%
\end{aligned}
$$

Where: $\Psi$ - matric suction $(\mathrm{kPa})$; and $\mathrm{w}$ - moisture of the filter paper.

And Eqs. 18 and 19, proposed by Fredlund and Xing (1994) [7], were used to adjust the retention curve:

$$
\begin{aligned}
& \theta=C(\Psi) \frac{\theta_{s}}{\ln \left[e+\left(\frac{\Psi}{a}\right)^{n}\right]^{m}} \\
& C(\Psi)=1-\frac{\ln \left[1+\Psi / \Psi_{r}\right]}{\ln \left[1+10^{6} / \Psi_{r}\right]}
\end{aligned}
$$

Where: $\theta_{\mathrm{s}}-$ soil volumetric moisture $(\%)$; $\mathrm{a}, \mathrm{m}, \mathrm{n}-$ adjustment parameters; $C(\Psi)$ - correction factor of Fredlund \& Xing (1994) [7]; $\psi$ - suction for which a moisture is searched $(\mathrm{kPa})$; and $\psi_{\mathrm{r}}$ : suction corresponding to residual volumetric moisture $(\mathrm{kPa})$.

\subsubsection{Double-Oedometer Test}

The double-oedometer test was performed with an undisturbed sample, collected from the mentioned Experimental Field. Therefore, the sample preparation consisted of carefully molding two specimens in a circular mold of five centimetres in diameter and two centimetres in height, transferring each sample to the oedometric cell, and later to the consolidation press.

The test started with the application of an initial stress of $25 \mathrm{kPa}$ for about 1 hour, to allow system accommodation. Before the loading process, one of the samples was flooded under this initial stress of $25 \mathrm{kPa}$, and the other one was loaded with its natural moisture (no flooding), whose suction was admitted as constant and estimated from the retention curve. To avoid drying out the flooded sample, water was repeatedly added to the oedometric cell during the test.

The loading phase basically consisted of the application of several stages of stresses, until the stabilization of strains. The duration of each stage was defined as the time needed until the deformation between two consecutive time intervals was less than $5 \%$ of the total soil deformation occurring until the previous time interval. The applied vertical stresses were doubled at each new loading stage $(50 \mathrm{kPa}, 100 \mathrm{kPa}, 200 \mathrm{kPa}$ and $400 \mathrm{kPa})$.

Fig. 4 shows oven-dried test specimens at the end of the test. It is important to note the difference in strains between the two specimens, which were resulted from the differences in moisture (and consequently, in suction values) in which the tests were performed. This yields stiffness is influenced by the suction values.

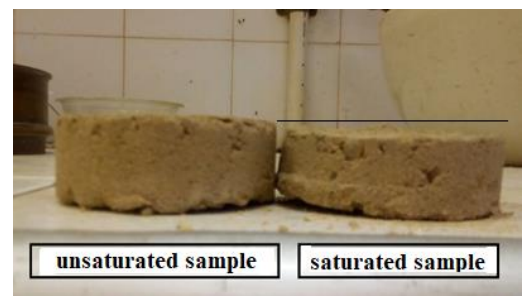

Fig. 4. Specimens of the double-oedometer test.

\section{Results and Discussion}

\subsection{Soil Characterization}

Table 1 shows the parameters obtained in the characterization tests, and Fig. 5 presents the grain-size curve of the soil.

Table 1. Summary of the parameters obtained in the characterization tests.

\begin{tabular}{c|c|c}
\hline Specification & Natural soil & Flooded soil \\
\hline USCS & SP & SP \\
LL, PL & NP & NP \\
Gs & 2.59 & 25.9 \\
w (\%) & 6.38 & 20.05 \\
S (\%) & 28.01 & 88.03 \\
$\gamma_{\mathrm{d}}\left(\mathrm{kN} / \mathrm{m}^{3}\right)$ & 15.98 & 15.98 \\
$\gamma\left(\mathrm{kN} / \mathrm{m}^{3}\right)$ & 17.00 & 19.18 \\
$\mathrm{E}$ & 0.59 & 0.59 \\
\hline
\end{tabular}

Where: USCS - Unified soil classification system; SP Poorly graded sand; LL - Liquid Limit; PL - Plastic Limit; NP -Non-plastic; Gs - Specific gravity of solid 
particle; $\mathrm{w}$ - moisture soil; $\mathrm{S}$ - Degree of saturation; $\gamma_{\mathrm{d}}-$ Dry unit weight; $\gamma$ - Unit weight; E - elastic modulus.

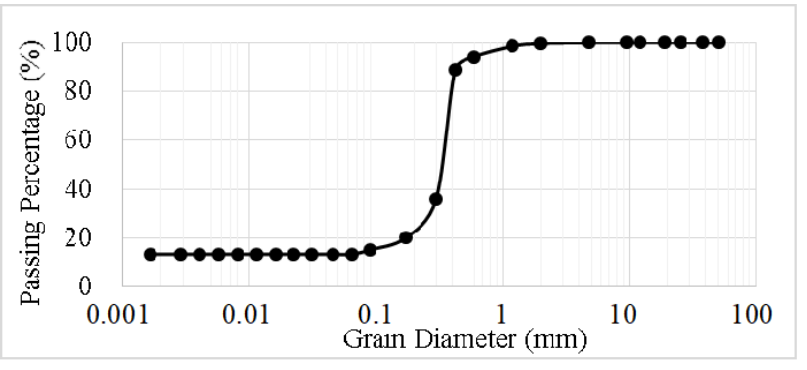

Fig. 5. Grain-size curve.

\subsection{Filter Paper}

Fig. 6 shows the retention curve resulting from the filter paper test and adjusted according to the model proposed by Fredlund and Xing (1994) [7]. The values of the fitting parameters used were: an equal to $4 \mathrm{kPa}, \mathrm{n}$ equal to 150 , and $m$ equal to 0.27 .

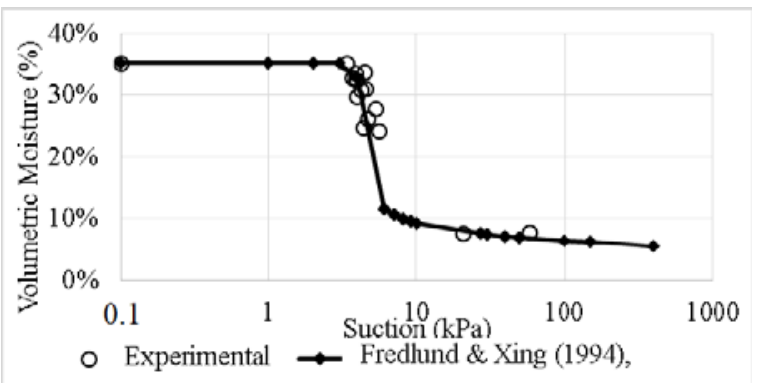

Fig. 6. Retention curve.

In order to validate the retention curve experimentally, Almeida (2018) [8] used the method of Arya and Dierolf (1989) [9] to produce retention curves for the same soil. It was noticed that the discrepancy is small between the forecast curve by the method Arya and Dierolf (1989) [9] and the experimental curve, which makes the result reliable.

\subsection{Double Oedometer Test}

Fig. 7 shows two curves of stress versus strain curve. The difference between them is due to the fact that, in the double-oedometer test, one specimen is loaded with previous saturation, and the other with no flooding. Table 2 shows the summary of the parameters obtained in the double-oedometer tests performed.

Table 2. Summary of the parameters obtained in the double-

\begin{tabular}{c|c|c}
\hline \multicolumn{3}{|c|}{ oedometer test. } \\
Specification & Natural soil & Flooded soil \\
\hline $\mathrm{E}_{\mathrm{EOD}}(\mathrm{kPa})$ & $5,997.00$ & $5,291.01$ \\
$\mathrm{E}(\mathrm{kPa})$ & $4,454.92$ & $3,930.46$ \\
\hline
\end{tabular}

\section{Numerical Analysis}

\subsection{Simulation of the Double Oedometer Test}

The analyses performed were mainly based on the doubleoedometer test, since the results of the test comprehend the input data for the program UNSTRUCT. The output data are the displacements suffered under the action of a given stress. Fig. 7 presents the result of the analysis, which is the stress versus strain curve, obtained by UNSTRUCT from the interpolation of the experimental curves.

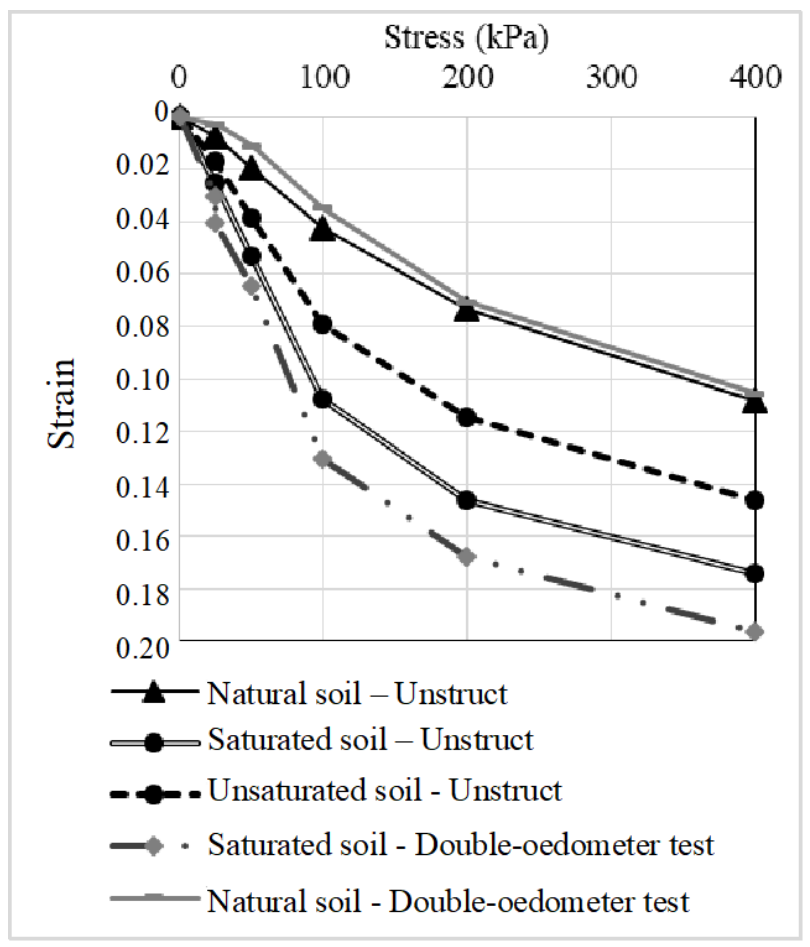

Fig. 7. Curve stress versus strain obtained by UNSTRUCT e by double-oedometer test.

\subsection{Behaviour of shallow foundations with different suction profiles}

The main objective of this work is to reproduce the behavior of a superficial strip foundation that would be laid on the unsaturated soil mass of the experimental field. Several analyses were conducted, with different suction profiles.

The soil SPT at the depth at which the sample was taken, at $0.8 \mathrm{~m}(\approx 1 \mathrm{~m})$, was approximately 2 . In the bulb of pressure, the SPT grew with the depth, until reaching values near 20 . In this case, in the numerical modelling, the soil was assumed as a homogeneous mass, and the value of the mean elastic modulus was calculated from the results of the double-oedometer test, extrapolating the results at the same rate as the SPT increases from $0.80 \mathrm{~m}$ to $10 \mathrm{~m}$, which is the depth of the soil mass simulated by UNSTRUCT analyzes. The results of the SPT were found in the work of Bonan (2017) [10].

In the analyses, both the load applied to the soil mass and the suction profile were varied. Each suction profile corresponded to a water level position and a flow rate. The data regarding these variables were combined to perform 
different analyses, each one using a pair "suction profileloading stage".

\subsubsection{Boundary Conditions}

The analyses were performed to study shallow foundations, by simulating a soil mass with a depth of $10 \mathrm{~m}$ and width of $36 \mathrm{~m}$. These dimensions ensure that the additional stresses applied are not influenced by the boundary conditions of the problem. As it is symmetrical, the graphs are only $18 \mathrm{~m}$ wide.

It should be noted that, in the simulation, the application of the surface load over the foundation was made $2 \mathrm{~m}$ below ground level. The foundation had a lateral dimension of $4 \mathrm{~m}$, but due to the symmetry, the mesh is only $2 \mathrm{~m}$ wide with load application, as shown in Fig. 8. In the simulations, the stress levels applied to the foundation soil were $100 \mathrm{kPa}, 200 \mathrm{kPa}$ and $400 \mathrm{kPa}$. The points of application are shown in Fig. 8.

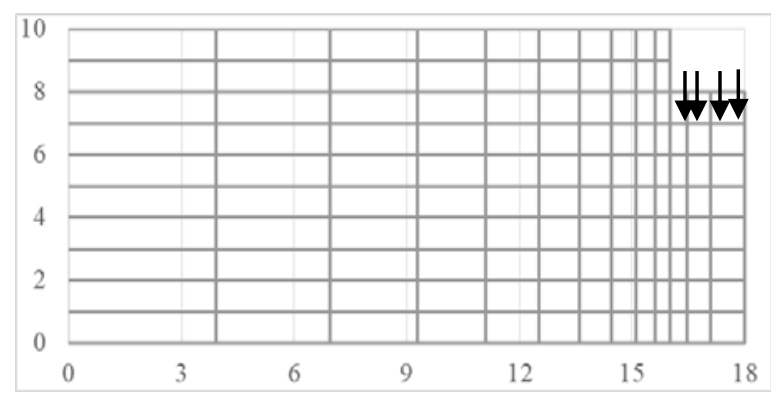

Fig. 8. Undisturbed mesh of finite elements.

\subsubsection{Suction Profiles}

In order to properly describe the variation of the matric suction along the entire depth of the soil mass - described through the finite element mesh for the numerical analysis - , the matric suction profiles utilized were obtained from Almeida (2018) [8]. In this context, a variation of the suction profile was made from the distance above water level, and the position of the water level itself, was varied in $10 \mathrm{~m}, 7 \mathrm{~m}$ and $5 \mathrm{~m}$. The only property obtained from the suction profiles was the variation of the matric suction along the entire depth of the soil mass.

The profiles were determined by the method proposed by Lu and Likos (2004) [11], and mathematical predictions were made by solving the flow equations with the initial boundary conditions. It is important to note that Darcy's law can be used to describe an unsaturated vertical flow, as long as the flow profile is stable. In this research, it will be considered the development of Gardner (1958) [12].

This method defines the matric suction as function of the hydraulic conductivity, flow rate and air-entry pressure. Lu e Likos (2004) [11] states that the hysteretic effects can be neglected in light of the advantages afforded by the simplified modelling method.

Five suction profiles were considered in this work: one hydrostatic, two that characterize the drying condition, and other two for the wetting condition. They were differentiated by the value of infiltration and evaporation rates (q) used for their determination.
It is also worth noting that flow rate profiles equal to zero $(q=0)$ represent the hydrostatic profile, flow rates profiles lower than zero $(\mathrm{q}<0)$ represent a downward flow (infiltration, which represent wetting profiles), and those with rates higher than zero $(\mathrm{q}>0)$ are drying profiles, since they have an upward flow (evaporation).

According to Almeida et al. (2020) [13], in the simulations, the variation of the water level around the depth found in a percussion test simulates its seasonal actual variation. In the SPT test at the Experimental Field, the water level was found at $7.35 \mathrm{~m}$. Hence, in the analyses, the water level was varied to values around $7.35 \mathrm{~m}-10 \mathrm{~m}, 7 \mathrm{~m}$ and $5 \mathrm{~m}$.

Table 3 shows the range of representative flow rates commonly encountered in the field under natural environmental conditions, presented by $\mathrm{Lu}$ and Likos (2004) [11], and used to calculate the suction profiles. Figs. 9, 10 and 11 show the variation of the water level and its corresponding suction profiles, for $10 \mathrm{~m}, 7 \mathrm{~m}$ and $5 \mathrm{~m}$, respectively.

Table 3. Infiltration and evaporation rates for the different flow directions.

\begin{tabular}{c|c}
\hline Flow direction & $\mathbf{q}(\mathbf{m} / \mathbf{s})$ \\
\hline Infiltration & $-3.14 \times 10^{-8}$ \\
Infiltration & $-3.14 \times 10^{-9}$ \\
Hydrostatic (no flow) & 0 \\
Evaporation & $1.15 \times 10^{-8}$ \\
Evaporation & $1.15 \times 10^{-9}$ \\
\hline
\end{tabular}

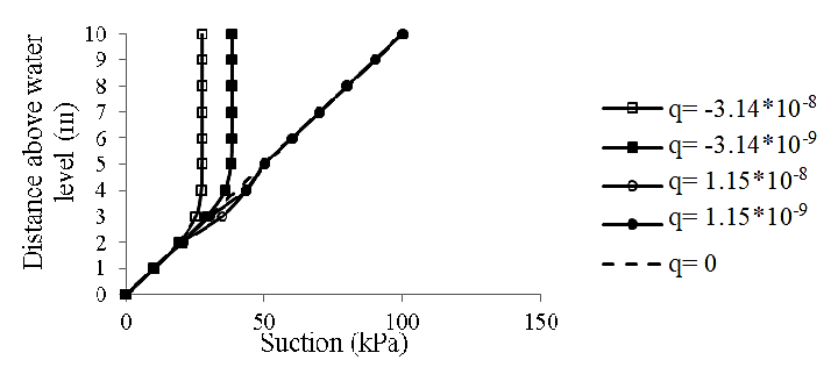

Fig. 9. Matric suction profiles at the water level of $10 \mathrm{~m}$.

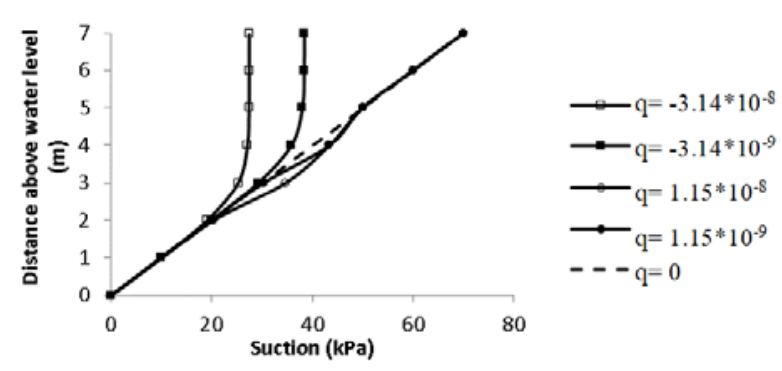

Fig. 10. Matric suction profiles at the water level of $7 \mathrm{~m}$. 


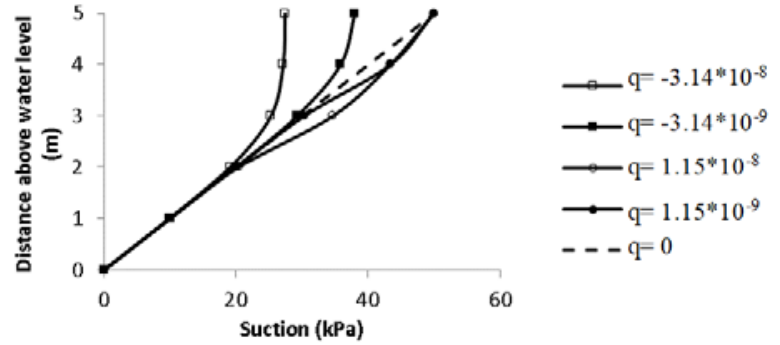

Fig. 11. Matric suction profiles at the water level of $5 \mathrm{~m}$.

In addition, it was possible to note that the wetting profiles (Figs. 9, 10 and 11) tended to vary the suction in the central segment of the water level distance, and to match the hydrostatic profile in the farthest reaches of the water level.

For all water levels though, the drying profiles were equal to the hydrostatic profile in the depths closer to the water level, and farther these depths were, more significant was the variation of the suction.

\subsubsection{Results}

The obtained results are deformed masses of soil for all the load levels applied $(100 \mathrm{kPa}, 200 \mathrm{kPa}$ and $400 \mathrm{kPa})$, in each of the five analyzed suction profiles. Fig. 12 shows a comparation between the maximum displacements for each load level applied at a given flow rate, corresponding to the suction profile presented for water level in $10 \mathrm{~m}$.

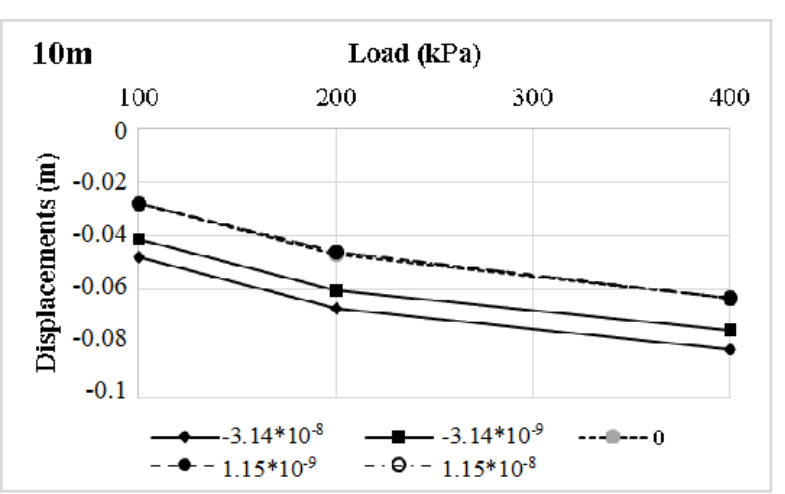

Fig. 12. Maximum displacements obtained with UNSTRUCT for water level in $10 \mathrm{~m}$.

It can be noted that the magnitude of the displacements in the curves referring to the suction profiles of $-3.14 \times 10^{-8}$ $\mathrm{m} / \mathrm{s}$ and $-3.14 \times 10^{-9} \mathrm{~m} / \mathrm{s}$ were larger. This happened because these profiles had a lower magnitude of the suction along the depth compared to the profiles with rates of $1.15 \times 10^{-8} \mathrm{~m} / \mathrm{s}$ and $1.15 \times 10^{-9} \mathrm{~m} / \mathrm{s}$, which had a much greater magnitude of the suction, and whose curves are grouped in Fig. 12.

Therefore, the greater the magnitude of suction (and thus the soil stiffness), the lower is the magnitude of the displacement (or settling) in the soil mass.

Figs. 13 and 14 show the variation of displacements for each suction profile analyzed for $7 \mathrm{~m}$ and $5 \mathrm{~m}$, respectively.

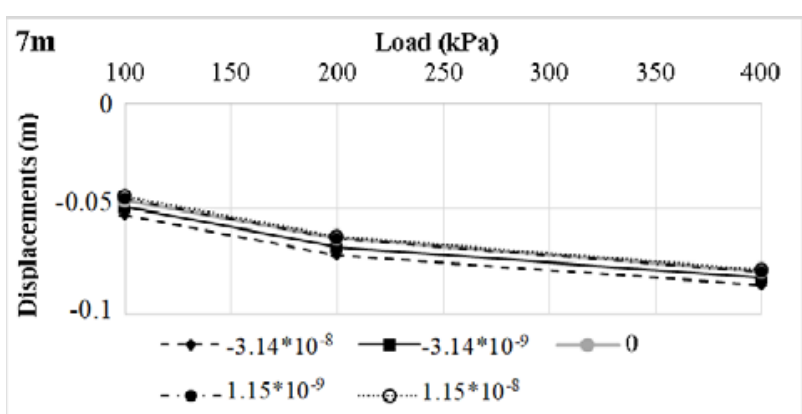

Fig. 13. Maximum displacements obtained with UNSTRUCT for water level in $7 \mathrm{~m}$.

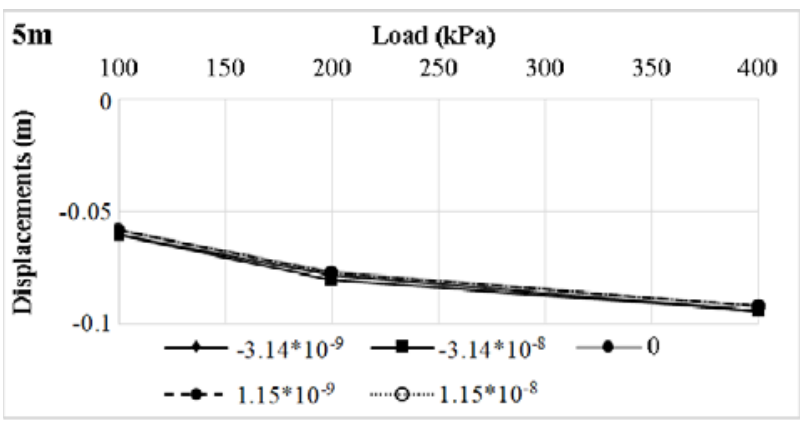

Fig. 14. Maximum displacements obtained with UNSTRUCT for water level in $5 \mathrm{~m}$.

Comparing the variation between the displacements in the three analyzed water levels, it is clear that the higher the variation of suction level is, the greater is the variation of settlement (or displacement) with the increase of stress and the change of flow rate (or better, with the changing of the suction profile).

It can be seen that the variation of displacement between one profile and another is significant in the scenario of greater suction (water level of $10 \mathrm{~m}$ ), and also that, in other profiles $(7 \mathrm{~m}$ and $5 \mathrm{~m})$, this change with the increase in the applied stress is much lower.

Fig. 15 shows a graph with maximum displacements versus flow rate, varying the water level (WL) in each curve for the maximum stresses. Hence, it is possible to compare the level of displacements with the change in the suction profile (flow rate) for the three water levels.

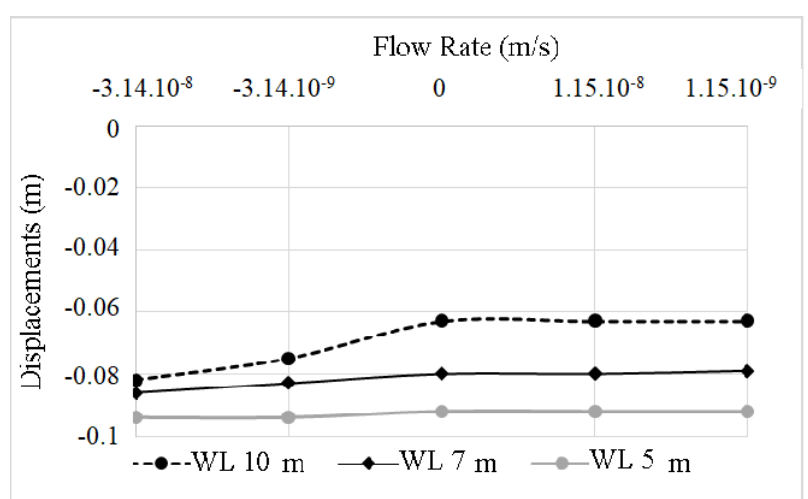

Fig. 15. Displacement versus flow rate.

When analyzing Fig. 15, it can be noted that the displacements vary more with changes in the flow rate for the water level curve of $10 \mathrm{~m}$ than that of the other water levels $(7 \mathrm{~m}$ and $5 \mathrm{~m})$. This is due to the higher suction in the water level of $10 \mathrm{~m}$. 
In addition, the lower displacement values happened for the water level of $10 \mathrm{~m}$, which had the highest suction values. Therefore, for finer soils, where suction reaches higher levels, this variation is larger and much more significant.

\section{Conclusions}

This work presented a practical and direct methodology for estimating settlements for shallow foundations laid in unsaturated soils.

By means of a double-oedometer test, it was possible to determine the stress-strain behaviour in oedometric conditions of two test bodies, one saturated and the other in the condition of low moisture, presumably the most extreme value of suction admitted to occur in the field.

From this test, the finite element program UNSTRUCT, initially proposed by Miranda (1988) [1] and modified by Silva Filho (1998) [2], was used to simulate a non-linear stress-strain behavior, performing an interpolation between the extreme values for the suction generated from the proposition of Lu and Likos (2004) [11].

It was concluded that the greater the changes in soil suction due to infiltration and evaporation, the greater the variation of settlement. As the soil used in this work was a sand poorly graded, this behaviour was more evident in the results for the water level in $10 \mathrm{~m}$, which had a greater suction.

The results obtained in the simulations for different suction profiles show that it is possible to make an approximate prediction of settlements in a shallow foundation using the proposed method described in this work. More precise results can be achieved by doing a specific analysis of the interaction between the soil and the atmosphere, which depends on geometrical boundaries and drainage conditions.

\section{Acknowledgements}

The authors are thankful to all who contributed the realization of the work, either direct or indirectly, in special to those who are part of the staff of the Laboratory of Soil Mechanics and Paving at the Federal University of Ceara, and to $\mathrm{CNPq}$, for funding the research that led to this work.

\section{References}

1. A. N. Miranda (1988). Behavior of small dams during initial filling. 229 p. Ph.D. Thesis, Colorado State University, Fort Collins.

2. F. C. Silva Filho (1998). Numerical Analysis of Problems in Unsaturated Soils: Modeling, Implementation and Practical Applications. $\mathrm{PhD}$ Thesis, Department of Engineering, Federal University of Rio de Janeiro, Rio de Janeiro, 236 p. (in portuguese)

3. R. F. Leme (2015). Methodology For The Construction Of Small Earth Dams In The Semi-Arid Region: Construction, Testing And Numerical
Modeling. PhD Tesis, Department of Hydraulic and Environmental Engineering, Federal University of Ceara, Fortaleza, 172 p. (in portuguese)

4. F. A. M. Marinho (2000) Soil suction measurement in soils and porous materials. In: Geo-Denver 2000: Short Course Notes on Unsaturated Soils in Engineering Practice, ASCE, Denver, Colorado.

5. M. G. F. Rios (2006). Behavior of a compacted landfill in the field and laboratory. MsC Dissertation, Department of Engineering, Federal University of Rio de Janeiro, Rio de Janeiro, 145 p. (in portuguese)

6. R. J. Chandler, M. S. Crilly, Montgomery-Smith, G. (1992). Method Of Assessing Clay Desiccation For Low-Rise-Building, Proceeding of the Institute of Civil Engineering, $\mathrm{n}^{\mathrm{o}}$ 2, p. 82-89. doi: 10.1680/icien.1992.18771

7. D. G. Fredlund; A. Xing, (1994). Equations For The Soil Water Characteristic Curve. Canadian Geotechnical Journal, v. 31, p. 521-532. doi: 10.1139/t94-061

8. M. M. R. Almeida (2018). Evaluation of Methods of Estimation of the Load Capacity of Direct Foundations in Unsaturated Soils. MsC Dissertation, Department of Hydraulic and Environmental Engineering, Federal University of Ceara, Fortaleza, 146 p. (in portuguese)

9. L. M. Arya, T. S. Dierolf (1989). Predicting soil moisture characteristics by particle-size distributions: an improved method to calculate pore radii from particle radii. In: M. T. Van Genuchten, F. J. Leij, L. J. Lund. (Eds). Proc. of the Int. Workshop on Indirect Methods for Estimating the Hydraulic Properties of Unsaturated Soils. Riverside, p. 115-124.

10. V. H. F. Bonan (2017). Evaluation of Methods of Estimation of the Load Capacity of Direct Foundations in Unsaturated Soils. MsC Dissertation, Department of Hydraulic and Environmental Engineering, Federal University of Ceará, Fortaleza, 146 p. (in portuguese).

11. N. Lu; W. Likos, (2004). Unsaturated soil mechanics. John Wiley and Sons, New York, NY, USA. ISBN: 978-0-471-44731-3

12. W. R. Gardner (1958). Some Steady-State of the Unsaturated Moisture Flow Equation with application to Evaporation from Water Table. Soil Science, v. 3, n. 85, p. 228-232. doi: 10.1097/00010694-195804000-00006

13. M. M. R. Almeida, F. C. Silva Filho, E. F. Lopes, Moura, A. S. (2020). Evaluation of Bearing Capacity Methods for Shallow Foundations in Unsaturated Soils. Geotecnia, n. 150, p. 87-106 (in portuguese). doi: 10.24849/j.geot.2020.150.06 